\title{
THERMAL MODIFICATION AS TOOL TO INCREASE HYDROPHOBICITY OF VENEERS
}

\author{
Anete Meija-Feldmane ${ }^{1}$, Errj Sansonetti ${ }^{2}$, Andris Morozovs ${ }^{1}$, Uldis Spulle $^{1}$ \\ ${ }^{1}$ Latvia University of Life Sciences and Technologies, Latvia; \\ ${ }^{2}$ Latvian State Institute of Wood Chemistry, Latvia \\ a.meija.feldmane@gmail.com, harrysansonetti@hotmail.com, \\ andris.morozovs@1lu.lv, uldis.spulle@1lu.lv
}

\begin{abstract}
Plywood is a well-known material with versatile usage due to its strength to weight ratio. One of the drawbacks of this material is its susceptibility to wood colouring and degradation by the influence of fungi. Fungal growth is directly related to the wood service conditions, among which moisture is the most important. One of the ways of reducing the wood moisture content by the increase of the hydrophobicity of the material is a thermal modification (TM). Thermowood $®$ is the most popular among many thermal treatment technologies. In this paper two less common TM methodologies - WTT and TERMOVUOTO® were used. The WTT technology is a closed process, where the thermal modification is conducted in water vapour environment with elevated pressure of about 7 bar, whereas the TERMOVUOTO® process is an open process with reduced pressure 0.25 bar. Three low-density wood species veneers were investigated - aspen (Populustremula L.), poplar (Populus x canadensisMoench) and birch (Betulapendula Roth). Aspen and birch veneers were treated according to WTT technology under previously determined optimal regime $160^{\circ} \mathrm{C} / 50 \mathrm{~min}$ and it was used as a reference. Poplar and birch veneers were treated according to the TERMOVUOTO ${ }^{\circledR}$ technology with four experimental regimes $204^{\circ} \mathrm{C} / 2 \mathrm{~h}, 214^{\circ} \mathrm{C} / 2 \mathrm{~h}, 217^{\circ} \mathrm{C} / 3 \mathrm{~h}, 218^{\circ} \mathrm{C} / 30 \mathrm{~min}$. The comparison of the contact angle values of un-treated, thermo-vacuum treated and hydro-thermal treated birch and poplar wood veneer surface was used to evaluate the thermal treatment method effect. The treatment process smoothed the hydrophobic properties of the treated veneer surfaces regardless of the process severity and hardwood species peculiarities. The obtained results make it easier to deal with the gluing process of thermally modified veneers, allowing not to consider the impact of the treatment regime.
\end{abstract}

Keywords: wood treatment technology, TERMOVUOTO, contact angle, modified veneers, surface energy.

\section{Introduction}

Wood is a copious material and people for thousands of years have been striving to find the best use for it. One of the approaches they have found is plywood manufacturing from wood. Plywood is a well-known material with versatile usage due to its strength to weight ratio. Comparing plywood with other materials, it has such drawbacks as swelling [1] and susceptibility to wood colouring and degradation fungi, especially in case of plywood made from hardwoods as richer in hemicelluloses compared to softwoods.

Fungal growth is directly related to the wood service conditions. There are four main factors that facilitate fungal attacks of wood - oxygen, high moisture content, optimum temperature $\left(24-32{ }^{\circ} \mathrm{C}\right)$ and a source of nutrients (primary hemicellulose and cellulose) [2].

Wood is hygroscopic material due to hydroxyl groups of cell wall polymers [3]. The hydroxyl groups, which are contained in the components of the wood cell wall, are responsible for the adsorption of moisture vapour from the surrounding air, thereby resulting in dimensional changes [4]. In theory, most, if not all, of the hydroxyl groups in hemicelluloses are accessible to moisture [5]. Wood modification process has become an attractive way to protect wood material against moisture content variations and wood decay. Heat treatment as a wood modification process is based on chemical degradation of wood polymers by heat transfer. It improves mainly the resistance of wood to decay and provides dimensional stability [6]. The typical range of the treatment temperatures is between $160{ }^{\circ} \mathrm{C}$ and $230{ }^{\circ} \mathrm{C}$ and it depends on the expected treatment intensity according to Hill [3]. The dimensional stabilization of wood is always associated with the transformation of wood from hydrophilic to hydrophobic [4]. There are different methods of wood thermal modification that can be applied and they might have a significant effect upon the properties of the thermal modification end product [3]. The environment has a significant influence upon the reaction chemistry occurring in the wood thermal treatment technologies [3], a separation of processes into moist and dry is advantageous or separation in closed and open reaction systems [7]. Heating of wood in the sealed reactor promotes condensation reactions between degradation products that can affect chemical changes taking place to the wood as well as the heating of wood in the presence of water or stream results in accelerated 
formation of organic acids (mainly acetic acid) that catalyse the hydrolysis of hemicelluloses and lesser extent of amorphous part of cellulose[3]. The thermo-vacuum process is an alternative technology for thermal modification of wood, where reduction of oxygen concentration inside the reactor, necessary to avoid wood combustion, is obtained by applying vacuum [8]. According to Hill, the thermo-vacuum is classified as a dry process in an open system [3], where all volatile compounds from reaction environment were continuously removed by the vacuum pump [9]. Heat treatment can significantly enhance the hydrophobic properties of wood, but the strength of heat-treated wood is lowered. This requires further research to improve its mechanical properties, while maintaining the advantages of the heat treatment [10]. Relatively little research has been made concerning the thermal treatments effect on the wetting characteristic of birch and aspen wood surfaces. The main objective of the present research was to evaluate the influence of the effects of the moist or dry thermal treatment technologies on the aspen and birch rotary-cut veneer surface wettability.

\section{Materials and methods}

Moist thermal treatment technology. Aspen (Populustremula L.) wood with size $280 \mathrm{~mm}$ (grain) $\times 270 \mathrm{~mm}$ (tangential) $\times 2 \mathrm{~mm}$ (radial) and birch (Betulapendula Roth) wood rotary - cut veneers with size $1000 \mathrm{~mm}$ (grain) $\times 350 \mathrm{~mm}$ (tangential) $\times 1.4 \mathrm{~mm}$ (radial) were treated according to the WTT technology with the previously determined optimal regime: temperature $160{ }^{\circ} \mathrm{C}$ and duration 50 minutes designed by Grinins et al. [11].

Dry thermal treatment technology under vacuum. Birch (Betulapendula Roth) wood with size $600 \mathrm{~mm}$ (grain) $\times 600 \mathrm{~mm}$ (tangential) $\times 1.4 \mathrm{~mm}$ (radial) and poplar (Populus $\times$ CanadensisMoench) wood rotary-cut veneers with size $600 \mathrm{~mm}$ (grain) $\times 600 \mathrm{~mm}$ (tangential) $\times 2 \mathrm{~mm}$ (radial) were treated according to the TERMOVUOTO ${ }^{\circ}$ process [12] with four experimental regimes (temperature/duration): $204^{\circ} \mathrm{C} / 2 \mathrm{~h}, 214^{\circ} \mathrm{C} / 2 \mathrm{~h}, 217^{\circ} \mathrm{C} / 3 \mathrm{~h}$, and $218^{\circ} \mathrm{C} / 30 \mathrm{~min}$ between aluminium plates in packs from 3 to 12 veneers in each under heat convective regime.

Sampling of veneers for contact angle measurements. The thermally treated veneers for contact angle measurement were selected with the mass loss by modification closest to the average mass loss of the whole batch. The un-treated (reference) veneers for contact angle measurement were selected with the density closest to the average: aspen wood with $440 \mathrm{~kg} \cdot \mathrm{m}^{-3}$, birch wood with $600 \mathrm{~kg} \cdot \mathrm{m}^{-3}$ and poplar wood with $300 \mathrm{~kg} \cdot \mathrm{m}^{-3}$.

Contact angle measurement of veneer surface. Samples with a size of $50 \mathrm{~mm} \times 150 \mathrm{~mm} \times$ thickness were cut for modified and un-treated veneers. Contact angles were measured without additional treatment of the sample surface. The sessile drop of distilled water with volume $10 \mu \mathrm{l}$ was placed on the sample surface with an electronic dosing device and the contact angle at the three-phase contact line perpendicular to wood grain was measured at the $5^{\text {th }}$ second after the drop placement on the surface to allow the drop to attain equilibrium on the surface [13]. Measurements were madewith the goniometer Dataphysics OCA20. 10 contact angle replicas were measured on each sample and their average contact angle from three samples was used for surface energy calculation. The surface free energies of modified and un-treated veneers surface were calculated according to the Equation of State or Neumann methodology[14] (1):

$$
\cos \theta=-1+2 \sqrt{\frac{\sigma_{s}}{\sigma_{l}}} e^{-\beta\left(\sigma_{l}-\sigma_{s}\right)^{2}},
$$

where $\theta$ - contact angle, ${ }^{\mathrm{o}}$;

$\sigma_{l}-$ surface tension of the liquid, $\mathrm{mJ} \cdot \mathrm{m}^{-2}$;

$\sigma_{s}-$ surface tension of the solid, $\mathrm{mJ} \cdot \mathrm{m}^{-2}$;

$\beta-0.0001247$ (empirical constant).

\section{Results and discussion}

The comparison of the contact angle values of un-treated, thermo-vacuum treated, and hydrothermal treated birch and poplar wood veneer surface was used to evaluate the thermal treatment method effect. For good adhesion, there must be molecular level contact between the adhesive and the wood surface, which includes a flow of adhesive over the substrate surface and into the irregularities 
of the surface to increase the contact area. A low contact angle indicates the used test liquid spreading on the surface with the formation of molecular-scale contact with the wood [15]. The mean values of the contact angle measurements for the modified and un-treated aspen, birch and poplar veneers are presented in Fig. 1.

The contact angle mean value $100 \pm 9^{\circ}$ of birch wood veneers was the highest among the investigated three kinds of un-treated wood species and exceeded $90^{\circ}$ that indicates the hydrophobicity of material itself. It means that there is low surface wettability, Papp [16] points out that un-treated birch (Betulapendula Roth.) contact angle is $72^{\circ}$. Liang [17] reveals that the contact angle of untreated birch veneers is $82^{\circ}$. The higher contact angle value of used birch wood veneer might be the result of extractives migration on the veneer's surface after peeling. The mean contact angle values of aspen wood and poplar wood veneer surfaces were $79 \pm 7^{\circ}$ and $64 \pm 3^{\circ}$ accordingly that is less than $90^{\circ}$. It means that there is water spreading on the surface. For untreated poplar Santoni[18] states the contact angle of $51^{\circ}$. Diouf [19] claims that contact angles are $68 \pm 8^{\circ}$ for hybrid poplar and $73 \pm 6^{\circ}$ for trembling aspen that coincides $78 \pm 8^{\circ}$ for aspen in this research. In order to entirely compare the results of contact angles there should be used the same measuring methodology - water drop size, result reading time and pre-treatment of samples.

The applied t-test results showed a statistically significant difference among all three wood species $p=7.5 \mathrm{E}-10$ between poplar and birch, $p=1.6 \mathrm{E}-5$ between aspen and birch and $p=5.4 \mathrm{E}-6$ between aspen and poplar. The cellulose content of aspen is higher than that of birch [20]. Birch is rich in extractives that can make the surface of this wood veneers more hydrophobic. Birch is also almost twice as dense as poplar wood.

The both used kinds of thermal modification of veneers had similar hydrophobicity increase on the tested veneer surfaces according to the contact angle values of treated veneer surfaces contact angle values shown in Fig.1, regardless of water presence in the hydro-thermal WTT technology and dry conditions in the TERMOVUOTO ${ }^{\circledR}$ technology. The similar effect on hydrophobicity increase showed all four treatment protocols of thermos-vacuum treatment according to the TERMOVUOTO ${ }^{\circledR}$ process, regardless of the process severity.

The water contact angle value influence on the thermally modified veneer surface increase is associated with the reduction of the veneer surface hydroxyl group content decrease due to hemicelluloses decomposition and formed monosaccharides dehydration with the formation of furfural $[3 ; 21 ; 22]$. In addition, celluloses during thermal modification increase in crystallinity by degrading the amorphous part or re-crystallize it in more hydrophobic crystallise cellulose [23].

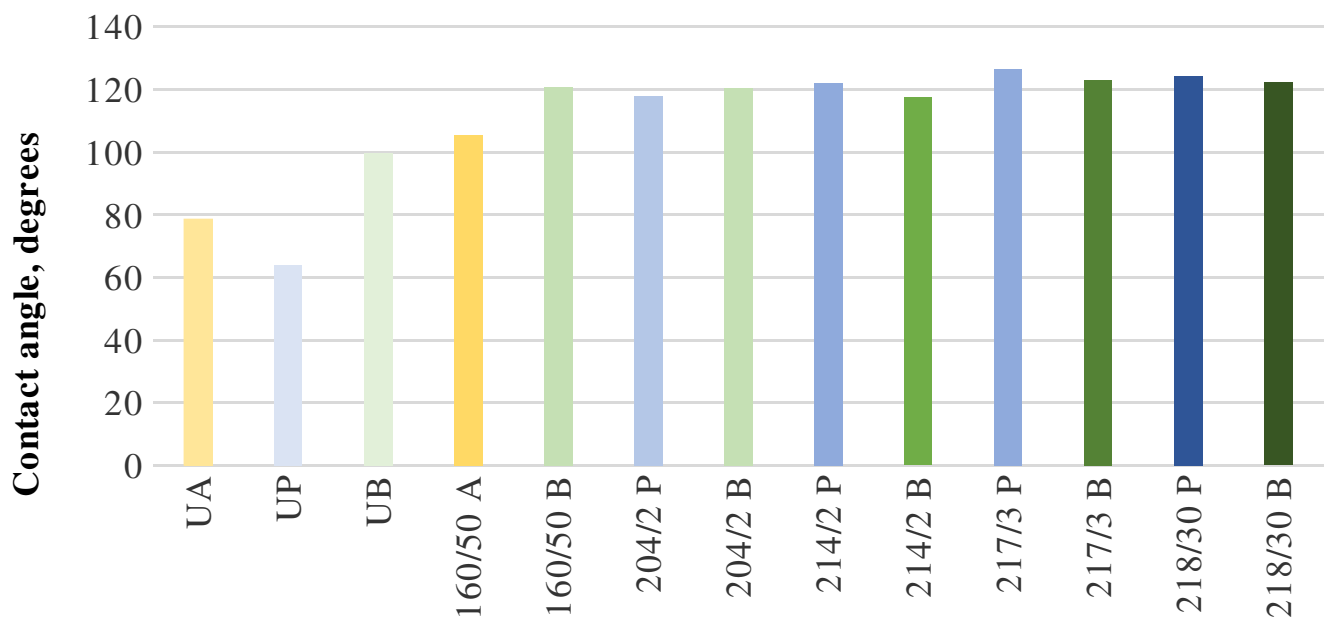

Fig.1. Contact angle of untreated and thermally modified veneer samples: $\mathrm{U}$ - untreated, A - aspen, B - birch, P - poplar

After modification the differences among the species decrease, which could be related to leaching of extractives from the wood material and also by fact that species of lower density present better stability to thermo-degradation than species of higher density [21]. Differences between poplar wood and birch wood after thermal modification are caused mainly due to degradation of hemicelluloses and 
are statistically significant only after modification with $214^{\circ} \mathrm{C} / 2 \mathrm{~h}$ regime $(p=0.003)$, as well as between aspen and birch after moist thermal treatment $160^{\circ} \mathrm{C} / 50$ min modification $(p=0.004)$. At $160^{\circ} \mathrm{C} / 50$ min differences between these two species of wood could occur due to favourable conditions for hydrolyse reactions to occur at this modification regime, so the contrast is considerable. Differences between poplar wood and birch wood at $214^{\circ} \mathrm{C} / 2 \mathrm{~h}$ are probably due to intrinsic species properties of the investigated samples.

Table 1

Surface free energy values of modified and untreated veneer samples after Equation of State method

\begin{tabular}{|c|c|c|}
\hline Wood specie & $\begin{array}{l}\text { Treatment } \\
\text { regime }\end{array}$ & $\begin{array}{c}\text { Surface free } \\
\text { energy, } \mathbf{m J} \cdot \mathbf{m}^{-2}\end{array}$ \\
\hline poplar & - & $45.4 \pm 2.3$ \\
\hline aspen & - & $36.4 \pm 1.7$ \\
\hline birch & - & $23.3 \pm 1.9$ \\
\hline aspen & $160^{\circ} \mathrm{C} / 50 \mathrm{~min}$ & $19.7 \pm 1.3$ \\
\hline birch & $160^{\circ} \mathrm{C} / 50 \mathrm{~min}$ & $11.2 \pm 1.2$ \\
\hline poplar & $204^{\circ} \mathrm{C} / 2 \mathrm{~h}$ & $12.7 \pm 0.9$ \\
\hline birch & $204^{\circ} \mathrm{C} / 2 \mathrm{~h}$ & $11.4 \pm 1.4$ \\
\hline poplar & $214^{\circ} \mathrm{C} / 2 \mathrm{~h}$ & $10.5 \pm 1.2$ \\
\hline birch & $214^{\circ} \mathrm{C} / 2 \mathrm{~h}$ & $12.9 \pm 0.8$ \\
\hline poplar & $217^{\circ} \mathrm{C} / 3 \mathrm{~h}$ & $8.5 \pm 0.9$ \\
\hline birch & $217^{\circ} \mathrm{C} / 3 \mathrm{~h}$ & $10.1 \pm 1.3$ \\
\hline poplar & $218^{\circ} \mathrm{C} / 30 \mathrm{~min}$ & $9.4 \pm 1.1$ \\
\hline birch & $218^{\circ} \mathrm{C} / 30 \mathrm{~min}$ & $10.5 \pm 1.0$ \\
\hline
\end{tabular}

The surface energy is a parameter that characterizes the surface wettability and adhesion that relates to glueability. According to Piao [24], Cooper and Nuttall subsequent conditions for spreading of a liquid on a solid substrate are established:

$$
S=\gamma_{S G}-\left(\gamma_{L G}+\gamma_{S L}\right)>0,
$$

where $S$-spreading force, $\mathrm{N} \cdot \mathrm{m}^{-1}$

$\gamma_{S G}$ - surface tension between solid-gas, $\mathrm{J} \cdot \mathrm{m}^{-2}$

$\gamma_{L G}$ - surface tension between liquid-gas, $\mathrm{J} \cdot \mathrm{m}^{-2}$

$\gamma_{S L}-$ surface tension between solid-liquid, $\mathrm{J} \cdot \mathrm{m}^{-2}$

For spreading $S>0$; for non-spreading $S<0$. For good wetting the surface tension of the solid must be greater than the surface tension of the liquid. It follows that wood surface free energy must be higher than the sum of liquid, e.g. non-cured glue and its interference with wood energy, to spread on the wood surface to provide the uninterrupted glue line formation (3):

$$
\gamma_{S G}>\gamma_{L G}+\gamma_{S L},
$$

where $\gamma_{S G}-$ surface tension between solid-gas, $\mathrm{J} \cdot \mathrm{m}^{-2}$

$\gamma_{L G}$ - surface tension between liquid-gas, $\mathrm{J} \cdot \mathrm{m}^{-2}$

$\gamma_{S L}$ - surface tension between solid-liquid, $\mathrm{J} \cdot \mathrm{m}^{-2}$

From the wood veneer surface energy values presented in Table 1 follows that thermally treated wood will have reduced adhesion with commonly used adhesives, although this parameter, with exception for aspen wood veneers heat-treated in moist environment conditions $160{ }^{\circ} \mathrm{C} / 50 \mathrm{~min}$, for the other modified veneer surface free energies has similar values in the range of $9.4 \mathrm{~mJ} \cdot \mathrm{m}^{-2}$ to $12.9 \mathrm{~mJ} \cdot{ }^{-2}$, so there practically is no need to use different adhesives and separate gluing regime.

\section{Conclusions}

1. The heat-vacuum treatment process provides aligned hydrophobicity of the treated veneer surfaces regardless of the process severity and hardwood species peculiarities. 
2. Thermal modification reduces differences of the surface free energy among species: the difference of free energy between untreated poplar and birch veneers was $22.1 \mathrm{~mJ} \cdot \mathrm{m}^{-2}$, but already at the mildest treatment regime $204^{\circ} \mathrm{C} / 2 \mathrm{~h}$ it shrank till $1.3 \mathrm{~mJ} \cdot \mathrm{m}^{-2}$.

3. The biggest surface free energy $45.5 \mathrm{~mJ} \cdot \mathrm{m}^{-2}$ among untreated wood species veneer samples had the poplar wood veneer, indicating the highest spreading pressure in the gluing process.

4. The obtained results of thermal - vacuum treatment of veneer surface evaluation with contact angle measurement make it easier to deal with the gluing process of thermally modified veneers, allowing not to consider the impact of the treatment regime severity.

5. The hydro-thermal veneers have slightly less hydrophobic wood surface.

\section{Acknowledgements}

The research was carried out within the project P5 "Plywood with improved durability" cofinanced by Implementation of Research Program at the Latvia University of Life Sciences and Technologies.

\section{References}

[1] Cirule D., Kuka E., Verovkins A. etc.,Restriction of liquid water spreading in overlaid plywood top veneer. Proceeding of International conference "Research for Rural Development", May 1618, 2018, Jelgava, Latvia, vol. 1, pp. 86-91.

[2] Li T., Cheng D., Avramidis S. etc. Response of hygroscopicity to heat treatment and its relation to durability of thermally modified wood. Construction and Building Materials., vol. 144, 2017, pp. 671-676.

[3] Hill C.A.S., Thermal Modification of Wood in Wood Modification: Chemical, Thermal and Other Processes. Chichester: Wiley and sons, 2006. 260 p.

[4] Sandberg D., Kutnar A., and G. Mantanis. Wood modification technologies - a review. iForest, vol. 10, 2017, pp 895-908.

[5] Rowell R.M., Moisture Properties in Handbook of wood chemistry and wood composites, Boca Raton: CRC press, 2005, pp. 77-98.

[6] Candelier K., Thevenon M.F., Petrissans A. etc. Control of wood thermal treatment and its effects on decay resistance: a review.Annals of Forest Science, vol. 73, 2016.

[7] Pelaez-Samaniego R.M., Yadama V., Lowell E. etc.A review of wood thermal pretreatments to improve wood composite properties. Wood Science and Technology, vol. 47, 2013, pp. 1285-1319.

[8] Sandak A., Sandak J., Allegretti O. Quality control of vacuum thermally modified wood with near infrared spectroscopy.Vacuum, vol. 114, 2015, pp. 44-48.

[9] Allegretti O., Brunetti M., Cuccui I. etc. , Thermo-vacuum modification of spruce (Picea Abies Karst) and fir (Abies Alba Mill.) wood. BioResources, vol. 7(3), 2012, pp. 3656-3669.

[10] Kocaefe D., Huang X., Kocaefe Y. Dimensional Stabilization of Wood. Current Forestry Reports, vol. 1 (3), 2015, pp. 151-161.

[11] Grinins J., Andersons B., Irbe I. etc. Thermo-hydro treated (THT) birch veneers for producing plywood with improved properties. Holzforschung, vol. 70, 2016.

[12] Sandak A., Sandak J., Cuccui I.. etc. Thermal modification of poplar veneers in vacuum conditions. Proceedings of International conference "European Conference on Wood Modification", October 26-27, 2015, Helsinki, Finland.

[13] Bekhta P., Proszyk S., Krystofiak T. etc. Effects of short-term thermomechanical densification on the structure and properties of wood veneers. Wood material Science and Engineering, vol. 0272, September, 2015, pp. 40-54.

[14]Li D., Neumann A. W. Equation of state for interfacial tensions of solid-liquid systems. Advances in Colloid and Interface Science, vol. 39, 1992, pp. 299-345.

[15]Hunt C. G., Frihart C. R., Dunky M. etc. Understanding Wood Bonds - Going Beyond What Meets the Eye: A Critical Review. Reviews of Adhesion and Adhesives,vol. 6 (4), 2019, pp.

[16]Papp E. A. Csiha C. "Contact angle as function of surface roughness of different wood species," Surfaces and Interfaces, vol. 8, no. April, 2017, pp. 54-59. 
[17]Liang T., Wang L. An environmentally safe and nondestructive process for bleaching birch veneer with peracetic acid. Journal of Cleaner Production, vol. 92, 2015, pp. 37-43

[18] Santoni I., Pizzo B. Effect of surface conditions related to machining and air exposure on wettability of different Mediterranean wood species. International Journal of Adhesion \& Adhesives, vol. 31 (7), 2011, pp. 743-753.

[19] Diouf P.N. et al., "Effects of thermo-hygro-mechanical densification on the surface characteristics of trembling aspen and hybrid poplar wood veneers," Appl. Surf. Sci., vol. 257, no. 8, 2011, pp. 3558-3564.

[20] Kocaefe D., Poncsak S., BolukY. Effect of thermal treatment on the chemical composition and mechanical properties of birch and aspen. Bioresouces, vol. 3, 2008, pp. 517-537.

[21] Chaouch M., Pétrissans M., Pétrissans A. etc. Use of wood elemental composition to predict heat treatment intensity and decay resistance of different softwood and hardwood species. Polymer Degradation and Stability, vol. 95, 2010, pp. 2255-2259.

[22] Mitsui K., Inagaki T., Tsuchikawa S. Monitoring of Hydroxyl Groups in Wood during Heat Treatment Using NIR Spectroscopy. Biomacromolecules, vol. 9(1), 2008, pp. 286-288.

[23] Chu D., Xue L., Zhang Y.etc. Surface Characteristics of Poplar Wood with High-Temperature Heat Treatment: Wettability and Surface Brittleness. BioResources, vol. 11(3), 2016, pp. 6948-6967.

[24]Piao C., Winandy J. E., ShupeT. F. From Hydrophilicity to Hydrophobicity: A critical Review Part 1: Wettability and surface behaviour.Wood and Fiber Science, vol. 42 (4), 2010, pp. 490-510. 